\section{Special Issue on HIV/AIDS: Infectious Disease Reports}

\section{Nitin K. Saksena, ${ }^{1}$ Dominic E. Dwyer, ${ }^{2}$ Richard Y. Zhao ${ }^{3}$ \\ ${ }^{1}$ Westmead Millennium Institute, Sidney, Australia; ${ }^{2}$ University of Sydney, Australia; ${ }^{3}$ University of Maryland School of Medicine, Baltimore, MD, USA}

\section{Dear Colleagues,}

Since the discovery of the first retrovirus by Robert Gallo in 1981, followed by the discovery of HIV in 1983 by Francoise Barre-Sinoussi and Luc Montagnier, the HIV/AIDS still remains a major global health problem.

According to the estimate of the World Health Organization, over 34 million people are currently infected with HIV, and by the year 2031 about 20 million more people will acquire HIV. In the absence of HIV vaccines, current antiretroviral therapies provide effective treatment and extend good quality of life to many of the HIV-infected individuals, but drug resistance and its continued transmission remains an imminent threat.

In the 30 years since the recognition of HIV/AIDS, clinicians, scientists, and public health officials have successfully worked together in making HIV/AIDS a manageable chronic disease in many part of the world. There is an appreciation of the progress made on treatment of the disease, diagnosis, prognosis and better understanding of the virus and its pathogenicity. Those vast investments of resources have thus not gone to waste and there is now a continued drive at all levels in not only eradicating HIV, but ultimately finding a cure to the disease.

This special issue of the Infectious Disease Reports (IDR) marks 30 years of HIV discovery and the World AIDS Day. It provides a snapshot on wide-ranging issues directly relevant to HIV/AIDS. These papers present exciting and insightful observations on the current state of HIV/AIDS and the topics of future relevance to HIV/AIDS research. The aim of this special issue is to provide readers an overview of the great progress made on many facets of HIV medicine to date, and to recognize the challenges that still remain to be met. This issue of IDR is also timely and provides readers with a
Correspondence: Nitin Saksena, Westmead Millennium Institute, Sidney, Australia.

E-mail: nitin.saksena@sydney.edu.au

Received for publication: 19 February 2013. Accepted for publication: 19 February 2013.

This work is licensed under a Creative Commons Attribution NonCommercial 3.0 License (CC BYNC 3.0).

(C) Copyright N.K. Saksena et al., 2013

Licensee PAGEPress, Italy

Infectious Disease Reports 2013; 5:sle

doi:10.4081/idr.2013.s1.e1

cutting edge report in the areas of viral evolution, diversity and recombination, drug therapy, resistance, problems and perspectives on HIV, HIV and neuro-pathogenesis, understanding of HIV-HCV co-infections, and emerging interests and concerns at the genomic levels.

Nitin K. Saksena, Dominic E. Dwyer, Richard Y. Zhao Guest Editors 